\title{
The cost of chronic dialysis in multiple myeloma
}

\author{
R.A. Coward
}

Department of Renal Medicine, Royal Preston Hospital, Sharoe Green Lane, Preston, UK.

\begin{abstract}
Summary: The complications and costs of chronic dialysis in 4 patients with renal failure due to multiple myeloma are presented. In three patients the paraprotein responded to chemotherapy though without recovery of renal function. These three patients are alive after 18,16 and 15 months of dialysis, the other dying after 7 months. Hospital admissions ranged from 26 to 74 days per year with infections accounting for 54 to $87 \%$ of admission days, $62.5 \%$ of which occurred during the first three months of dialysis treatment, with an incidence of 2.4 to 6.9 admissions episodes per year.

An in-house audit of our chronic dialysis patients indicated that treatment of myeloma patients is 5-33\% more expensive. The extra cost in such high risk patients is mostly due to the greater number and longer duration of hospital admissions for infection. The other extra costs (in decreasing value) of blood products, antibiotics and chemotherapy are relatively small in comparison to in-patient treatment.
\end{abstract}

\section{Introduction}

Several published series have demonstrated that patients with severe chronic renal failure secondary to multiple myeloma can be successfully dialysed..$^{1-3}$

Such patients would otherwise have died of renal failure rather than myeloma. There is little published information on the complications encountered by the myeloma patients on chronic dialysis and hence the cost of offering such treatment.

Bacterial infections are a major cause of morbidity and mortality in myeloma patients, ${ }^{4}$ with azotaemia being suggested as a further independent risk factor to increase the infection risk. ${ }^{5}$ Patients suffering from myeloma are often elderly ( $>55$ years of age) and hence would be classed as high risk dialysis patients independent of the systemic disease from which they suffer. $^{6}$ They would also be unsuitable for renal transplantation. Such restraints imply a more difficult and expensive treatment regime.

In the modern climate of medical care in the United Kingdom, increasing emphasis has been placed, not on what is technically possible, rather what is feasible within limited health care resources. ${ }^{7}$ Though chronic renal failure programmes have received preferential treatment, the acceptance rate within the United Kingdom is still amongst the lowest in Europe. ${ }^{8}$ It is against this background that this paper examines the medical, economic and social implications of offering dialysis treatment to such high risk patients. We try and answer the questions: Is it justifiable to use long

Correspondence: R.A. Coward, D.M., M.R.C.P.

Accepted: 30 November 1988 term dialysis to keep such patients alive? Do these $\vec{z}$ patients have a good quality of life? How much more does it cost to treat these patients than normal dialysis $\overrightarrow{0}$ patients? What causes this difference?

\section{Materials and methods}

\section{Patients}

During the two year period from August 1985 to $\overrightarrow{\vec{O}}$ August 1987, four patients suffering from myeloma and severe renal failure were offered chronic dialysis at $\bar{T}$ the Royal Preston Hospital. All patients had multiple myeloma based on the MRC criteria.'

All patients presented with severe renal failure (serum creatinine $>295 \mu \mathrm{mol} / \mathrm{l}$ ). In 3 , dialysis was not deemed necessary from between 2 and 7 months from presentation when initial treatment was by $\delta$ haemodialysis, though one patient (number 4) was subsequently trained for continuous ambulatory 0 peritoneal dialysis (CAPD), the remaining three being on a hospital maintenance haemodialysis programme.

\section{Chemotherapy}

All patients had intermittent chemotherapy dependent 0 N on blood count. The different regimes used were: $\frac{\omega}{\sigma}$ patient 1 - intravenous vincristine, adriamycin and oral dexamethasone. ${ }^{10}$ Prophylactic co-trimoxazole $\stackrel{\varrho}{\subset}$

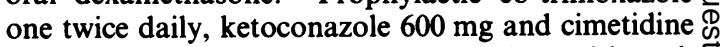
$400 \mathrm{mg}$ twice daily, were given for 7 days with each $?$

(C) The Fellowship of Postgraduate Medicine, $1989 \frac{\mathrm{D}}{\mathrm{D}}$ 
course. " Patient 2 was entered into the MRC Vth Myeloma trial, being drawn to receive the ABCM protocol (6-week cycle, i.v. adriamycin and BiCNU, oral melphalan and cyclophosphamide). Patients 3 and 4 were treated with oral melphalan and prednisolone.

\section{Costing}

Drug costs were based on hospital contract prices including value added tax. Blood product costings were according to Department of Health and Social Security (DHSS) circular H.N. (87)15. In-patient (acute medicine) fully inclusive costs of $£ 77.19$ per day were based on the DHSS estimates. (DHSS Circular, Financial Matters, July 1987 [FMN7/87]). This was collated from a set of speciality costs by regression analysis from the 1985-86 costing returns from each health district in the United Kingdom. A prospective internal audit over 3 months on the Royal Preston Hospital Dialysis Unit with 20 maintenance haemodialysis and 19 CAPD patients, gave a cost of f110 per maintenance haemodialysis treatment and $£ 19.32$ for four 2-litre. CAPD exchanges per day (unpublished data). This includes all staff salaries (medical, nursing, paramedical, administration, catering, pathology and radiology) and all consumables.

\section{Antibiotics}

First line treatment for patients with clinical evidence of a severe infection was 10 days' intravenous gentamicin and piperacillin. For subclavian line infection, the line was removed and intravenous vancomycin $1 \mathrm{~g}$ was given, to be followed by a 7-day course of oral flucloxacillin. Herpes was treated with acyclovir. Peritonitis during CAPD was treated with 10 days of intraperitoneal vancomycin and gentamicin.

\section{Results}

\section{Response to chemotherapy}

In all patients urinary light chain excretion became an unreliable indicator of disease activity because of oligoanuria. In two patients (numbers 2 and 4), the serum paraprotein was no longer detectable by immunoelectrophoresis and patient 3 showed a maximum $23 \%$ decrease in serum paraprotein.

These results indicate that patients 2,3 and 4 responded to chemotherapy. However, patient 1 had clinical evidence of continuing amyloid deposition, and hence lack of response.

Three of the patients are still alive on chronic dialysis (August 1988 - all $>15$ months dialysis). Patient 1 died 10 months after presentation and 7 months after commencing dialysis. The cause of death was bronchopneumonia complicated by amyloid.

\section{Admissions}

Though patient 4 had the largest total number of days in hospital (87), 39 of these days were explained by 'CAPD training', prolonged because of drug allergy, hypotension and oedema. Excluding CAPD training, the admissions for the four patients were from 26 to 74 days per year (Table I). The first 3 months from the start of dialysis and excluding CAPD training accounted for $62.5 \%$ of the year's admission.

\section{Infections and antibiotics}

Admission for infections accounted for between 23 and 46 days/dialysis/year and 2.4 and 6.9 admission episodes/year (Table I). Three of the patients also had minor infections treated on an out-patient basis,

Table I Hospital admissions

\begin{tabular}{|c|c|c|c|c|c|c|c|c|c|}
\hline \multirow[t]{2}{*}{ Patient } & \multicolumn{4}{|c|}{ Number of admissions } & \multicolumn{4}{|c|}{ Admissions for infection } & \multirow{2}{*}{$\begin{array}{l}\begin{array}{c}\text { Days for } \\
\text { infection }\end{array} \\
\text { Total days }\end{array}$} \\
\hline & Total no & $\begin{array}{c}\text { Admissions } \\
\text { per year }\end{array}$ & Days & Days/y & Total & $\begin{array}{c}\text { Admissions } \\
\text { per year }\end{array}$ & Days & Days/y & \\
\hline 1 & 6 & 10.3 & 34 & 58 & 4 & 6.9 & 27 & 46 & 79 \\
\hline 2 & 6 & 4 & 39 & 26 & 4 & 2.7 & 34 & 23 & 87 \\
\hline 3 & 14 & 10.5 & 92 & 74 & 6 & 4.5 & 50 & 37 & 54 \\
\hline 4 & 6 & 4.8 & $48^{*}$ & 39 & 3 & 2.4 & 36 & 29 & 73 \\
\hline Mean & & 6.9 & & 45.6 & & 3.6 & & 31.5 & \\
\hline
\end{tabular}

*Excluding in patient number 4, 39 days for CAPD dialysis training. 
Table II Sites of infection and antibiotic costings

\begin{tabular}{|c|c|c|c|c|c|c|c|c|c|c|}
\hline \multirow{3}{*}{ Patient } & & & \multirow{3}{*}{$\begin{array}{l}\text { Admissions } \\
\text { for infection }\end{array}$} & \multicolumn{7}{|c|}{ Site } \\
\hline & \multicolumn{2}{|c|}{ - No of infections } & & \multirow[t]{2}{*}{ Chest } & \multirow[t]{2}{*}{$\begin{array}{l}\text { Subclavian } \\
\text { line }\end{array}$} & \multirow[t]{2}{*}{ Peritonitis } & \multirow[t]{2}{*}{ Herpes } & \multirow[t]{2}{*}{ Other } & \multicolumn{2}{|c|}{$\begin{array}{c}\text { Cost of } \\
\text { antibiotics }\end{array}$} \\
\hline & Total & $\begin{array}{c}\text { with } \\
\text { neutropenia* }\end{array}$ & & & & & & & Total & $\begin{array}{l}\text { per } \\
\text { year }\end{array}$ \\
\hline 1 & 4 & 1 & 4 & 3 & 1 & 0 & 0 & 0 & $£ 332$ & $£ 579$ \\
\hline 2 & 5 & 1 & 4 & 2 & 1 & 0 & 2 & 0 & £308 & $£ 205$ \\
\hline 3 & 9 & 4 & 6 & 5 & 3 & 0 & 0 & 1 & $£ 510$ & $£ 383$ \\
\hline 4 & 6 & 0 & 3 & 3 & 0 & 2 & 1 & 0 & $£ 392$ & $£ 314$ \\
\hline Total & 24 & 6 & 17 & 13 & 5 & 2 & 3 & 1 & & \\
\hline
\end{tabular}

Patient 1 received prophylactic antibiotics during chemotherapy (see text).

*Total white count $<3.0 \times 10^{9} / 1$.

infection accounting for $54 \%-87 \%$ of admission days excluding training periods for CAPD (Table I). Only 6 $(25 \%)$ of the total 24 infection episodes were associated with neutropenia (total white count $\left.<3.0 \times 10^{9} / 1\right)$. However, patient 3 had four infections $(44 \%)$ associated with neutropenia. In the group as a whole, chest infections accounted for $54 \%$ of episodes with subclavian dialysis line infections $21 \%$. All patients were initially dialysed via a temporary dual lumen subclavian cannula (Marhurkher Quinton Ltd), the cannula being used for between one week (patient 4) to 6 months (patient 3).

The total cost of antibiotics ranged from $£ 308.00$ to $£ 510.00$ with an annual cost of $£ 205.00$ to $£ 579.00$ (Table II).

\section{Blood products}

Blood transfusions were given for symptomatic reasons and if the haemoglobin fell below $6.5 \mathrm{~g} / \mathrm{dl}$. All patients required regular and frequent transfusions with a range of 11 to 56 units/dialysis/year. Transfusion requirements were higher within the first 6 months of dialysis and during chemotherapy. Patient 1 received the greatest number of transfusions (33 units, $56 /$ dialysis/year) but also had the most aggressive chemotherapy regime and the poorest paraprotein response. Plasma protein fraction $(5 \%)$ was also given to three patients $(3-17$ bottles) to treat hypotension and hypoalbuminaemia during dialysis.

The costing of blood products ranged from $£ 243-£ 988$ per patient, corrected to $£ 162-£ 1,018$ per dialysis year, (Table III).

\section{Costing}

There was a wide range in the costing for each variable (Table III), the most expensive variable being dialysis itself with CAPD being markedly cheaper than haemodialysis. Chemotherapy accounted for the least cost with the differences between patients explained by the much higher price of intravenous agents as compared to oral melphalan and prednisolone.

'In-patient' costs reflecting the number of days in hospital was, apart from dialysis itself, the largest cost and also the most variable.

Table III Costs of different items in patients' care

\begin{tabular}{|c|c|c|c|c|c|c|c|c|c|c|c|c|}
\hline \multirow[t]{2}{*}{ Patient } & \multicolumn{2}{|c|}{ Dialysis costs* } & \multicolumn{2}{|c|}{ In-patient costst } & \multicolumn{2}{|c|}{ Antibiotics } & \multicolumn{2}{|c|}{ Blood products } & \multicolumn{2}{|c|}{ Chemotherapy } & \multicolumn{2}{|c|}{ Overall } \\
\hline & Total & per year & Total & $y r$ & Total & $y r$ & Total & $y r$ & Total & $y r$ & Total & $y r$ \\
\hline 1 & $£ 10010$ & $£ 17160$ & $£ 2618$ & $£ 4488$ & $£ 338$ & $£ 579$ & $£ 594$ & $£ 1018$ & $£ 348$ & $£ 597$ & $£ 13908$ & $£ 23842$ \\
\hline 2 & $£ 25740$ & $£ 17160$ & $£ 2002$ & $£ 1334$ & $£ 308$ & $£ 205$ & $£ 243$ & $£ 162$ & $£ 300$ & $£ 200$ & $£ 28593$ & $£ 19062$ \\
\hline 3 & $£ 21450$ & $£ 17160$ & $£ 5313$ & $£ 3985$ & $£ 510$ & $£ 383$ & $£ 988$ & $£ 741$ & $£ 73$ & $£ 55$ & $£ 28334$ & $£ 21250$ \\
\hline 4 & $£ 9089$ & $£ 7161$ & $£ 3696$ & $£ 2952$ & $£ 392$ & $£ 314$ & $£ 801$ & $£ 640$ & $£ 20$ & $£ 16$ & $£ 17601$ & $£ 13603$ \\
\hline Mean & & & & $£ 3564$ & & $£ 332$ & & $£ 563$ & & $£ 159$ & & \\
\hline
\end{tabular}

*Dialysis costs, haemodialysis $£ 110.00$ per treatment, 4 CAPD 2 litre exchanges $£ 19.92$ per day; $\uparrow$ Cost/day $£ 77.00$, (includes 39 days CAPD training for patient number 4). 


\section{Quality of life}

Only one patient (number 3) was in full time employment when he presented with myeloma. Despite numerous admissions and the restrictions of maintenance haemodialysis he has managed to continue his business as a market gardener. Patient 2, a retired civil servant, experienced initial debility associated with chemotherapy though enjoys a full active retirement, recently holidaying in Portugal on dialysis. Patient 4 , a sister in a convent, had to relinquish her duties of caring for other frail and elderly nuns to be looked after herself. Patient 1 , a retired army sergeant major, never regained his prepresentation state of health. He also suffered from episodes of depression associated with steroid therapy and infections and considered discontinuing treatment on two occasions.

\section{Discussion}

Historically, renal failure is second only to infection as the most common cause of death in multiple myeloma, ${ }^{12}$ with renal insufficiency at presentation associated with a poor prognosis. ${ }^{13}$ More recently, it has been shown that with correction of dehydration, ${ }^{14}$ and prompt attention to reversible features, a significant number of patients can regain renal function. ${ }^{15}$

There does, however, remain a group of patients with multiple myeloma and chronic irreversible renal failure with either an acute or insidious onset. Such patients are accepted on chronic dialysis programmes. Myeloma accounts for $0.6 \%$ of patients $15-64$ years of age and $1.7 \%$ patients $>65$ years of age on the European Dialysis and Transplant Register in $1984-5 .^{8}$ Myeloma is therefore more frequent than tuberculosis and approximately equal to systemic lupus erythematosus as a cause for chronic dialysis.

Cosio suggested that in patients with myeloma and chronic renal failure, the prevention of death by dialysis resulted in a prognosis similar to patients without renal insufficiency. ${ }^{1}$ If this is the case, are the complications we experience similar to those in myeloma patients without renal insufficiency?

Bacterial infections are a major cause of morbidity and mortality in all myeloma patients with an incidence of 0.8 to 2.22 infections per patient/year, ${ }^{16,17}$ with lower respiratory tract infections being the most frequent, as also shown in our series. The data presented in this paper give an incidence of 2.4 to 6.9 infections per patient/year, higher than previous myeloma series, yet confirmed by a preliminary report by Tam et al. ${ }^{18}$ of 8 myeloma patients treated by CAPD with an average of 2.5 infections/year/patient with a range of $0-6.3$. Such results would suggest that myeloma patients on dialysis have a greater risk of infection than those without renal insufficiency, contradicting Cosio's statement. ${ }^{1}$

Decreased clearance of anti-mitotic drugs in renal failure and possible marrow suppression could contribute to an increased risk of infection. This does not seem to be relevant as our observation is that only $25 \%$ of infections were associated with neutropenia.

Infections were more common within the first 3 months from presentation when the highest number of admissions occurred, a finding also observed by Perri et $a .^{5}$ In our series, this could at least be partly accounted for by subclavian dialysis cannula exit site infections. Such infections are well recognized in non-myeloma patients and though our numbers are small, there does not appear to be an increased risk or contra-indication to the use of this technique.

Herpes infections have infrequently been described in patients with myeloma, ${ }^{19,20}$ yet two patients had three infections, all of which were of a minor nature and responded to acyclovir.

Our only CAPD patient had two episodes of peritonitis in 15 months, the same rate as a recent large study. ${ }^{21}$ The report by Tam et al. ${ }^{18}$ on myeloma patients gave an average peritonitis rate of 3.2 episodes per year with a range of 1.3 to 7.5 episodes per year. A worrying observation that needs further confirmation if CAPD is to be considered in treating such patients.

Costing of dialysis treatment depends on what is included, the type of dialysis and in which country the treatment is performed. ${ }^{6,22,23}$ Despite these differences, it is widely accepted that hospital based maintenance haemodialysis is more expensive than home dialysis whether it is CAPD or haemodialysis.

Our own figures of $£ 110.00$ per hospital haemodialysis treatment, and $£ 19.32$ /day for CAPD are comparable with previously published figures. ${ }^{25}$ Our costs in myeloma patients for maintenance haemodialysis of $£ 19,062-£ 23,842$ per annum and CAPD $£ 13,600$ per.annum compare with published figures of $£ 12,500-£ 15,300$ for maintenance haemodialysis, ${ }^{23}$ and $£ 8,400-£ 11,000$ for CAPD. ${ }^{24}$ Using our audit costings and admission rates from the 7 centre dialysis study, ${ }^{21}$ we calculate maintenance haemodialysis at $£ 18,146$ per annum and CAPD at $£ 8,403$ per annum. This latter figure excludes training. The costs for the myeloma patients in our study are between $5 \%$ and $33 \%$ more expensive than these calculated figures. The costing differences in myeloma patients are due to the extra costs of chemotherapy, blood products, antibiotics and additional hospitalization. A major variable in the calculations is the number of admissions per year, a factor which we have shown is greatly increased in myeloma patients. The recent 7 centre dialysis study ${ }^{21}$ of 338 CAPD and 175 haemodialysis patients shows a hospitalization rate of 
14.9 days per year on CAPD and 12.8 per year for haemodialysis patients. These figures are obviously much lower than our data.

An early report from the Mayo Clinic $^{2}$ suggested an average of 12 days hospitalization/year in their myeloma patients on chronic dialysis, whilst the Leicester experience ${ }^{18}$ gave 75 days hospitalization/ year/patient with a range of $31-152$ days. Our findings fit between these two extremes.

The duration of hospital admission adds greatly to the annual cost. We do not suggest that only myeloma patients are at risk of such admissions, yet it seems a common pattern both from Leicester and our own experience, that myeloma patients on chronic dialysis, have more frequent and longer durations of hospitalization.

\section{References}

1. Cosio, F.G., Pence, T.V., Shapiro, F.P. \& Kjellistrand, C.M. Severe renal failure in multiple myeloma. Clin Nephrol 1981, 15: 206-210.

2. Johnson, W.G., Kyle, R.A. \& Dahlburg, P.J. Dialysis in the treatment of multiple myeloma. Mayo Clin Proc 1980, 55: 65-72.

3. Coward, R.A., Mallick, N.P. \& Delamore, I.W. Should patients with renal failure associated with myeloma be dialysed? Br Med J 1983, 287: 1575-1578.

4. Jacobson, D.R. \& Zolla-Pazner, S. Immunosuppression and infection in multiple myeloma. Semin Oncol 1986, 13: $282-290$.

5. Perri, R.T., Hebbel, R.P. \& Oken, M.M. Influence of treatment and response status on infection risk in multiple myeloma. JAMA 1981, 71: 935-939.

6. Wood, I.T., Mallick, N.P. \& Wing, A.J. Prediction of resources needed to achieve the national target for treatment of renal failure. $\mathrm{Br}$ Med $J$ 1987, 294: 1467-1470.

7. Williams, A. Coronary artery by-pass grafting, an economic appraisal. Br Med J 1985, 291: 326-329.

8. Report of E.D.T.A. Registry. Demography of dialysis and transplantation in Europe 1984. Nephrol Dial Transplant 1986, 1: 1-8.

9. Medical Research Council. Treatment comparisons in the third MRC myelomatosis trial. Br J Cancer 1980, 42: 823-830.

10. Anderson, H. Scarffe, J.H., Lambert, M. et al. VAD chemotherapy, toxicity and efficacy in patients with multiple myeloma and other lymphoid malignancies. Haematol Oncol in press.

11. Barlogie, B., Smith, L. \& Alexanian, R. Effective treatment of advanced multiple myeloma refactory to alkylating agents. $N$ Engl J Med 1984, 310: 1353-1356.

12. Kyle, R.A. Multiple myeloma - A review of 869 cases. Mayo Clin Proc 1975, 50: 29-40.

13. Medical Research Council working party on leukaemia in adults. Prognostic features in the third MRC myelomatosis trial. Br J Cancer 1980, 42: 831-840.
From our own experience and other published data, we conclude that long-term survival on dialysis is possible for myeloma patients and a good quality of life is achieved if a response to chemotherapy is obtained. Chronic dialysis in myeloma is $5-33 \%$ more expensive than routine dialysis and the extra cost is mostly due to the number and duration of hospital admissions for infection. The costs of chemotherapy, antibiotics and blood products are relatively small in comparison to the 'hotel costs' of in-patient treatment.

\section{Acknowledgements}

We would like to thank Miss Julie Marginson for typing the manuscript, Mr Mark Youlton for performing the internal audit, Miss Jane Boyland for costing the drugs and Dr N.P. Mallick for critical comments.

14. Medical Research Council working party on leukaemia in adults. Analysis and management of renal failure in the fourth MRC myelomatosis trial. Br Med J 1984, 288: $1411-1416$.

15. Rota, S., Mangenot, B., Baudouim, B. et al. Multiple myeloma and severe renal failure: a clinico-pathological study of outcome and prognosis in 34 patients. Medicine (Baltimore) 1987, 66: 126-137.

16. Fahey, J.L., Scoggins, R., Utz, J.P. et al. Infections, antibody response and gamma globulin components ince multiple myeloma and macroglobulinaemia. Am J Med? 1963, 35: 698-707.

17. Twomey, J.T. Infections complicating multiple myeloma and chronic lymphocytic leukaemia. Arch Int Med 1973, 132: $562-565$.

18. Tam, F., Russel, G.I., Smith, B.A. \& Walls, J. CAPD in end stage renal failure due to myeloma. Abstract Proceedings International Society of Nephrology 1987, 201.

19. Wright, E.T., Winer, L. \& Hills, B. Herpes zoster and malignancy. Arch Dermatol 1961, 84: 242-244.

20. Cohen, H.J. \& Randle, R.W. Managing the complications of plasma cell myeloma. Arch Intern Med 1975, 135: $177-184$.

21. Gokal, R., Baillard, R., Bogle, S. et al. Multicentre study on outcome of treatment in patients in continuous ambulatory peritoneal dialysis and haemodialysis. Nephrol Dial Transplant 1987, 2: 172-178.

22. Manis, T. \& Friedman, E.A. Dialytic therapy for irreversible uremia. N Engl J Med 1979, 301: 1260-1265.

23. Mancini,P.V. The cost of treating end stage renal failure. Draft paper for DHSS, Elephant and Castle, London. June 1984.

24. Beardsworth, S.F. \& Goldsmith, H.J. CAPD on Merseyside - cost effectiveness. Health Trends 1982, 14: 89-91.

25. Durie, B.G.M. \& Salmon, S.E. A clinical staging system for multiple myeloma. Cancer 1975, 36: 842-854. 